\section{Variant histone H3.3 is deposited at sites of nucleosomal displacement throughout transcribed genes while active histone modifications show a promoter-proximal bias}

\author{
Christiane Wirbelauer, Oliver Bell, and \\ Dirk Schübeler ${ }^{1}$
}

Friedrich Miescher Institute for Biomedical Research, 4058 Basel, Switzerland

Deposition of variant histones provides a mechanism to reset and to potentially specify chromatin states. We determined the distribution of $\mathrm{H} 3$ and its variant $\mathrm{H} 3.3$ relative to chromatin structure and elongating polymerase. H3.3 is enriched throughout active genes similar to polymerase, yet its distribution is very distinct from that of several euchromatic histone modifications, which are highly biased toward the $5^{\prime}$ part of active genes. Upon gene induction we observe displacement of both $\mathrm{H} 3$ and H3.3 followed by selective deposition of H3.3. These results support a model in which $\mathrm{H} 3.3$ deposition compensates for transcription-coupled nucleosomal displacement yet does not predetermine tail modifications.

Supplemental material is available at http://www.genesdev.org.

Received April 22, 2005; revised version accepted May 30, 2005.

Recent studies have changed the perception of chromatin, the complex of DNA and bound histones in eukaryotes. It is now established that histones are dynamically modified at multiple residues and thus are not static DNA packaging material (Felsenfeld and Groudine 2003). As defined post-translational modifications have been attributed to DNA repair, transcriptional activation, and repression, it has been hypothesized that they mediate specific functional readouts of DNA (Strahl and Allis 2000) and that chromatin structure changes play a central part in any DNA templated event (Turner 2002). Importantly, the cellular repertoire of modulating chromatin is not limited to modification of histones, but also includes site-specific deposition of variant histones (Henikoff et al. 2004; Sarma and Reinberg 2005). As these variants can replace existing histones, they provide a cellular system to erase modification patterns and, due to their unique sequence, could furthermore act as upstream signals to predetermine chromatin states. In the

[Keywords: Chromatin; Drosophila; H3.3; histone modification; histone variants; transcription]

${ }^{1}$ Corresponding author.

E-MAIL dirk@fmi.ch; FAX 41-61-6973976.

Article and publication are at http://www.genesdev.org/cgi/doi/10.1101/ gad.347705. case of $\mathrm{H} 3$, at least two variants are expressed in addition to the major $\mathrm{H} 3$, which is deposited at newly replicated DNA during the $\mathrm{S}$ phase of the cell cycle: the centromere-specific variant CenH3 and H3.3. In Drosophila, fusion proteins of GFP and H3.3 lacking the N terminus colocalize in interphase with active ribosomal repeats (Ahmad and Henikoff 2002b) and on polytene chromosomes at heat shock or ecdysone-induced puffs (Schwartz and Ahmad 2005), suggesting incorporation of this variant outside of $S$ phase at sites of high transcriptional activity. The link of H3.3 deposition and transcriptional activation is further supported by a higher abundance of euchromatic histone modifications on endogenous H3.3 compared with H3 (McKittrick et al. 2004). This observation led to the hypothesis that H3.3 might be an upstream determinant of chromatin structure at active genes, in which case one might predict that sites of H3.3 deposition could have a uniform pattern of post-translational modifications.

Deposition of variant histones requires the removal or disassembly of existing nucleosomes. Incorporation could take place in a coordinated exchange reaction or in a two-step process in which deposition occurs subsequent to displacement. Recent studies showed conclusively that nucleosomes are displaced in trans at a promoter (Reinke and Horz 2003; Korber et al. 2004), and reduced detection of nucleosomes was reported at highly transcribed genes in Saccharomyces cerevisiae (Bernstein et al. 2004; Lee et al. 2004). However, it remains to be shown if this temporary reduced detection during transcription is a consequence of, for example, partial disassembly or if it actually reflects transcriptioncoupled eviction, which could precede H3.3 deposition.

Here we use chromatin immunoprecipitation (ChIP) of $\mathrm{H} 3$ and $\mathrm{H} 3.3$ to determine the chromosomal positions of variant incorporation and ask if these have uniform tail modifications. Furthermore, we analyze the specificity and kinetics of $\mathrm{H} 3$ and H3.3 displacement and deposition during and subsequent to gene induction.

\section{Results and Discussion}

\section{Stably expressed H3 and H3.3 show differential} localization and modification

Drosophila histone H3 and H3.3 differ at only four positions, which hinders their distinction by immunochemical methods. To discriminate both variants in vivo, we added short peptide tags to their $\mathrm{C}$ terminus and stably expressed them as full-length proteins in Drosophila Kc cells. Resulting cell pools displayed similar expression level for both proteins (Fig. 1A), and immunostaining revealed that each variant has a distinct nuclear distribution in interphase nuclei (Fig. 1B). Histone ${ }^{\star} \mathrm{H} 3$ localization is indistinguishable from that of DNA, as would be expected from a replication-coupled deposition during the $\mathrm{S}$ phase of the cell cycle. The interphase distribution of ${ }^{\star} \mathrm{H} 3.3$ is remarkably different, however, as this variant is largely absent from the transcriptionally inert heterochromatin, which in many Drosophila cell types, including Kc cells, clusters into a single chromocenter. The nuclear localization of ${ }^{\star} \mathrm{H} 3.3$ in Kc cells is similar to that of dimethylated Lys 4 (H3K4me2; modification nomenclature according to 

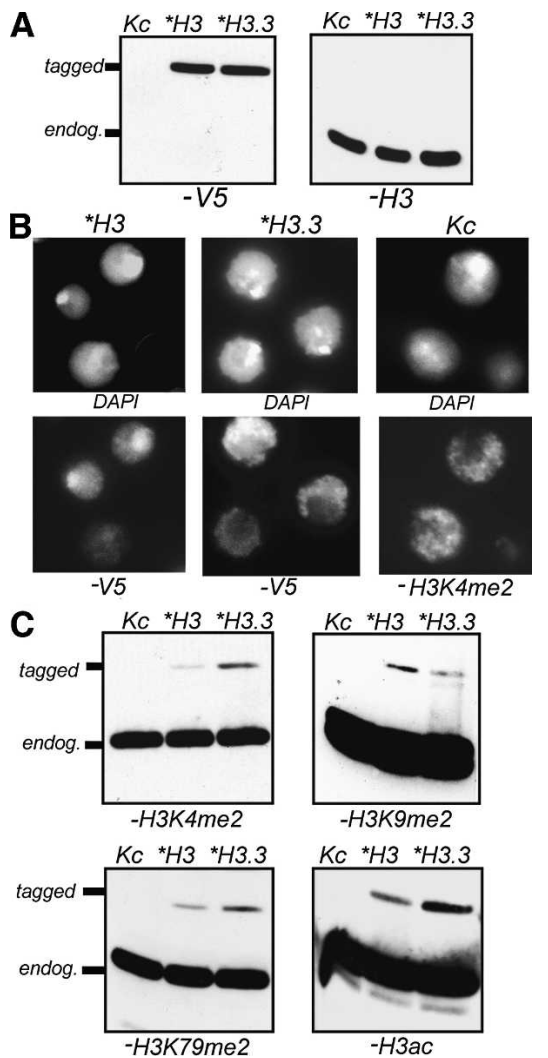

Figure 1. Expression, nuclear localization, and covalent modification of epitope-tagged $\mathrm{H} 3$ and H3.3. (A) A V5 epitope was added to the $\mathrm{C}$ terminus of $\mathrm{dH} 3.3$ and $\mathrm{dH} 3$ and expressed under the control of a constitutively active promoter. Cells stably transfected with either ${ }^{\star} \mathrm{H} 3.3$ or ${ }^{\star} \mathrm{H} 3$ show a similar level of tagged histones by Western blot analysis detected with an $\alpha \mathrm{V} 5$ antibody. Endogenous H3 detected with an antibody against the $\mathrm{C}$ terminus of $\mathrm{H} 3$ and $\mathrm{H} 3.3$ $(\alpha \mathrm{H} 3)$ serves as a loading control. The shown exposure time for $\alpha \mathrm{H} 3$ is below saturation for the endogenous $\mathrm{H} 3$ pool and therefore tagged histones are not visualized due to their relatively low amount $(\sim 1 / 50$ of endogenous, see Fig. 1C). (B) Cells expressing ${ }^{\star} \mathrm{H} 3$ and ${ }^{\star} \mathrm{H} 3.3$ were stained with DAPI for DNA and expressed variants were detected with the $\alpha \mathrm{V} 5$ antibody. The heterochromatin-containing chromocenter is visible as a strong DAPI-stained region in interphase. ${ }^{\star} \mathrm{H} 3$ staining is very similar to DAPI, suggesting that this variant is evenly distributed throughout the genome, while ${ }^{\star} \mathrm{H} 3.3$ is largely excluded from the chromocenter, similar to H3K4me2. (C) Western blot analysis of covalent modifications on variant histones. Histone preparations from cell pools expressing ${ }^{\star} \mathrm{H} 3$ or ${ }^{\star} \mathrm{H} 3.3$ were analyzed with antibodies against different $\mathrm{H} 3$ modifications. Euchromatic modifications (H3K4me2, H3K79me2, H3ac) are more abundant at ${ }^{\star} \mathrm{H} 3.3$, while the heterochromatin-specific modification H3K9me2 is more abundant at ${ }^{*} \mathrm{H} 3$. This analysis furthermore indicates that ${ }^{\star} \mathrm{H} 3$ and ${ }^{\star} \mathrm{H} 3.3$ represent $\sim 2 \%$ of the cellular $\mathrm{H} 3$ pool.

Turner [2005]), a modification that has been linked to active transcription, suggesting exclusive H3.3 incorporation in euchromatin (Fig. 1B).

Distinct post-translational modifications of endogenous H3 and H3.3 have been identified after biochemical separation of both proteins from Drosophila Kc cells (McKittrick et al. 2004). To determine if ectopically expressed variants recapitulate these differences, we performed Western blot analysis, since the tagged variants can be distinguished from endogenous $\mathrm{H} 3$ due to a slightly increased mass. In this analysis, ${ }^{\star} \mathrm{H} 3.3$ contains higher amounts of acetylated Lys 9 and Lys 14 (H3ac) and of di- and trimethylated Lys 4 (H3K4me2, H3K4me3) and dimethylated Lys 79 (H3K79me2) (Fig. 1C; data not shown). All four modifications have previously been shown to be more abundant at active genes in Drosophila Kc cells (Schübeler et al. 2004) and to be enriched at the endogenous H3.3 protein (McKittrick et al. 2004). On the other hand, ${ }^{\star} \mathrm{H} 3$ contains higher levels of Lys 9 dimethylation (H3K9me2) (Fig. 1C), a modification, which is highly abundant in Drosophila heterochromatin (Schotta et al. 2002) and on endogenous H3 (McKittrick et al. 2004), consistent with the presence of ${ }^{\star} \mathrm{H} 3$ in this nuclear compartment (Fig. 1B).

Thus, ectopically expressed full-length histone $\mathrm{H} 3$ and H3.3 containing short C-terminal epitope tags show a nuclear distribution and post-translational modifications similar to that reported for the endogenous proteins. This suggests that differential deposition is determined primarily by specific interaction with distinct nucleosome assembly systems, as previously shown for human H3 and H3.3 (Tagami et al. 2004).

\section{H3.3-specific histone modifications are more prevalent at the $5^{\prime}$ end of active genes}

H3.3 is enriched for tail modifications of active chromatin, and thus it has been hypothesized that deposition of H3.3 and the targeting of these modifications are connected. Recent studies in S. cerevisiae (Santos-Rosa et al. 2003) as well as in human cells (Bernstein et al. 2005) showed that $\mathrm{H} 3 \mathrm{~K} 4 \mathrm{me}$ is not distributed uniformly throughout active genes, but instead is more prevalent toward the $5^{\prime}$ end. To determine if a similar bias exists in Drosophila, we measured several euchromatic histone modifications (H3K4me2, H3K4me3, H3K79me2, and $\mathrm{H} 3 \mathrm{ac})$ at 36 sites along nine genes by ChIP. Approximate expression levels for each gene were obtained from a previous microarray analysis, which showed that two of the nine genes are transcriptionally inactive, while the others express at variable levels (Schübeler et al. 2002). Primers were chosen at different positions throughout each gene and enrichment for a modification was quantified by real-time PCR. The resulting enrichments were normalized to an intergenic control sequence and to nucleosomal abundance, which was measured using an antibody recognizing the $\mathrm{C}$ terminus of both $\mathrm{H} 3$ and H3.3 (Supplementary Fig. 1). Figure 2 displays the resulting distribution for all nine genes analyzed. Neither inactive gene displays enrichment above background for any of the four modifications. In contrast all seven measured active genes showed enrichment for all four modifications, in agreement with our previous observation that these modifications coincide at active genes (Schübeler et al. 2004). Importantly, a stronger presence of each modification is evident toward the $5^{\prime}$ part at each active gene (Fig. 2A). The strength of this $5^{\prime}$ bias is variable between modifications but is not limited to a higher level at the promoter. Instead we find a gradual decrease along the transcribed region. This is also evident if averages for all tested sequences are calculated based on distances to start site (Fig. 2B), again illustrating a gradual decrease in the abundance of euchromatic modifications.

This remarkable bias for a number of modifications in Drosophila is in agreement with previous reports for H3K4me in human cells (Bernstein et al. 2005) and extends this observation to $\mathrm{H} 3 \mathrm{~K} 79 \mathrm{me} 2$ and $\mathrm{H} 3 \mathrm{ac}$. While this distribution is likely to reflect different steps in transcript elongation or polymerase complex composi- 


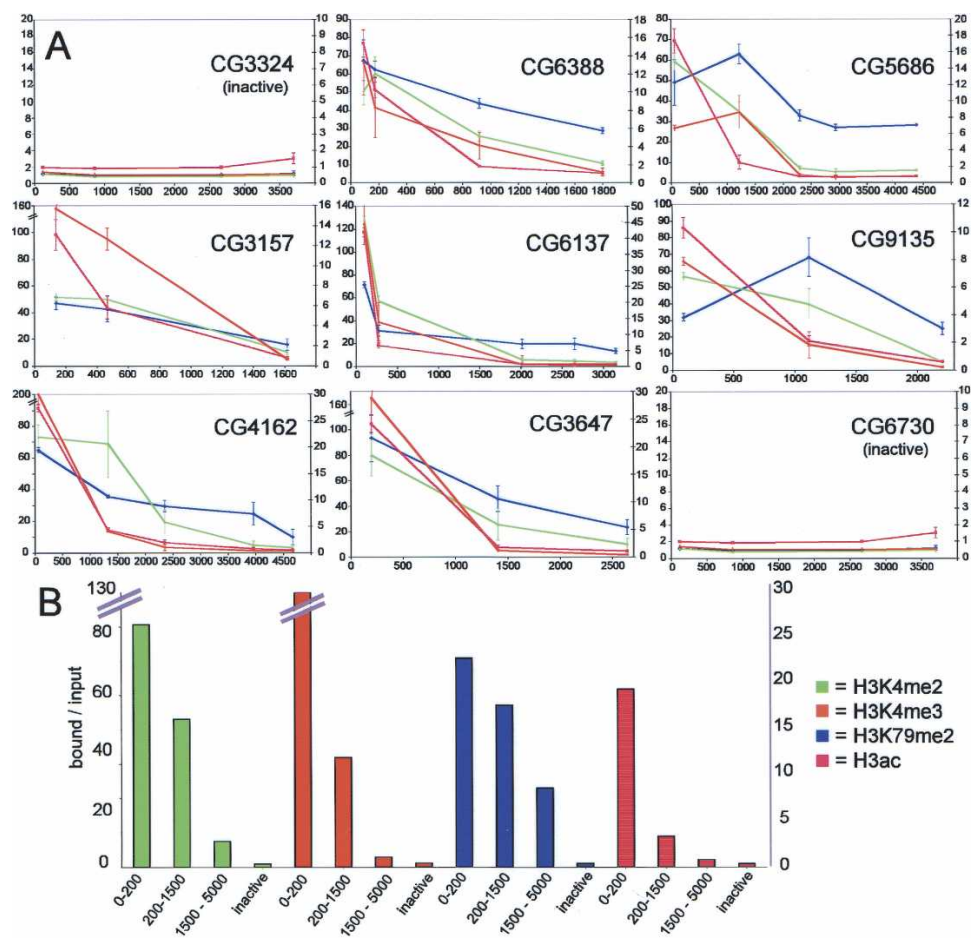

Figure 2. Distribution of several euchromatic histone modifications. After ChIP using antibodies against $\mathrm{H} 3 \mathrm{~K} 4 \mathrm{me} 2$, $\mathrm{H} 3 \mathrm{~K} 4 \mathrm{me} 3$, H3K79me2, and $\mathrm{H} 3 \mathrm{ac}$, enrichment was measured by real-time PCR and normalized for nucleosomal abundance. $(A)$ Shown is the average and SD from three independent repeats. (Red line) H3ac; (blue) H3K79me2; (orange) H3K4me3; (green) H3K4me2. X-axis reflects base-pair position relative to transcriptional start. $Y$-axis reflects enrichment (Bound over Input). See the right scale for H3ac, and the left for other modifications. Numbers in graphs are gene IDs. In the case of several genes, enrichment for H3K4me3 at the promoter-proximal probe is higher than the scale chosen for representation (CG3157 $=154$, CG4162 $=213$, CG3647 $=183$ ). (B) Average enrichments were calculated for all probes in active genes. Probes were grouped according to distance to transcriptional start site $(0-200 \mathrm{bp}, n=9$; 200-1500 bp, $n=7 ; 1500$ or more, $n=13$ ). All probes at inactive genes were grouped separately. For every group, the average enrichment for each modification was calculated. Values for $\mathrm{H} 3 \mathrm{ac}$ are according to the right $\mathrm{Y}$-axis; values for others are according to the left $Y$-axis.

tion (for reviews, see Sims et al. 2004; Peters and Schübeler 2005), it also raises the possibility that it mirrors distinct distributions of histone variants.

\section{H3.3 is distributed evenly along active genes similar to elongating polymerase}

To determine if histone H3.3 is specifically incorporated at single-copy RNA PollI transcribed genes and to relate this to the observed complex pattern of histone modifications, we performed ChIP analysis of the epitopetagged ${ }^{\star} \mathrm{H} 3$ and ${ }^{\star} \mathrm{H} 3.3$ variants. Relative abundance of H3.3 was calculated as a ratio of enrichment in cells expressing ${ }^{\star} \mathrm{H} 3.3$ over that in cells expressing ${ }^{\star} \mathrm{H} 3$. This calculation was chosen to exclude any influence of variable nucleosomal occupancy between chromosomal locations. Figure $3 \mathrm{~A}$ shows the resulting enrichments for the same set of nine genes for which we generated histone modification profiles. In this analysis, all active genes show a higher abundance of $\mathrm{H} 3.3$ than any inactive gene, suggesting that transcription is required for incorporation of H3.3. While this is in agreement with previous cytological studies (Ahmad and Henikoff 2002b;
Schwartz and Ahmad 2005), it furthermore shows that H3.3 incorporation is not limited to highly transcribed or multigenic loci. The higher resolution of ChIP analysis also allowed us to determine if incorporation occurs selectively at promoter or transcribed regions. Notably, all our promoter-proximal probes $(0-200 \mathrm{bp})$ would also detect H3.3 incorporation immediately $5^{\prime}$ of the initiation site, as our assay resolution is $500 \mathrm{bp}$ based on the size of the sheared chromatin. However, we do not find evidence for preferential incorporation of $\mathrm{H} 3.3$ at promoter regions, since in six of seven genes tested promoter-proximal probes show enrichment similar to promoter-distal probes. This result is in contrast to a recent study reporting preferential promoter incorporation of N-terminal-tagged H3.3 in mammalian cells (Chow et al. 2005). In that study, neither H3 distribution nor nucleosomal abundance was analyzed. While we cannot exclude that H3.3 deposition is different between mammalian cells and Drosophila, the results of our analysis of nine different genes strongly suggests that H3.3 deposition occurs throughout transcribed regions. Similarly, we find no decrease in H3.3 abundance along transcribed sequences, as we show for euchromatic histone modifications (Fig. 3C). Consequently, while $\mathrm{H} 3.3$ incorporation is restricted to active genes, it neither occurs preferentially at the promoter nor does it display a $5^{\prime}$ bias similar to that of many euchromatic histone modifications. Thus, it appears unlikely that H3.3 deposition alone is sufficient to predetermine posttranslational modifications.

As H3.3 and euchromatic modifications are distinct, we next asked if $\mathrm{H} 3.3$ deposition follows the activity of polymerase. The C-terminal domain (CTD) of PolII consists of 42 repeats in Drosophila, and its hyperphosphorylation is associated with elongation (O'Brien et al. 1994). Ser 5 phosphorylation (Ser5-P) of CTD has been observed at promoters and coding regions (Komarnitsky et al. 2000), and a rather uniform distribution of this hyperphosphorylation has recently been demonstrated at a number of active genes in Drosophila cells (Boehm et al. 2003) and in S. cerevisiae (Kizer et al. 2005). A ChIP analysis using an antibody against Ser5-P of CTD reveals elongating polymerase at all active genes tested (Fig. 3B). At many genes we find higher levels of polymerase at the promoter, which is in agreement with previous observations (Jones et al. 2004) and potentially reflects early events in the acquisition of elongation competence. Importantly, however, the distribution along the transcribed region downstream of the promoter is rather uniform and very similar to that of H3.3 (Fig. $3 \mathrm{C})$, suggesting that polymerase elongation and H3.3 deposition are linked.

\section{Gene induction leads to nucleosomal loss followed by preferential incorporation of the H3.3 variant}

Transcription requires DNA unwinding, and the fate of nucleosomes during this process is controversial. Different models have been proposed to explain how the compact chromatin structure allows passage of the large polymerase complex. These include nucleosomal trans- 


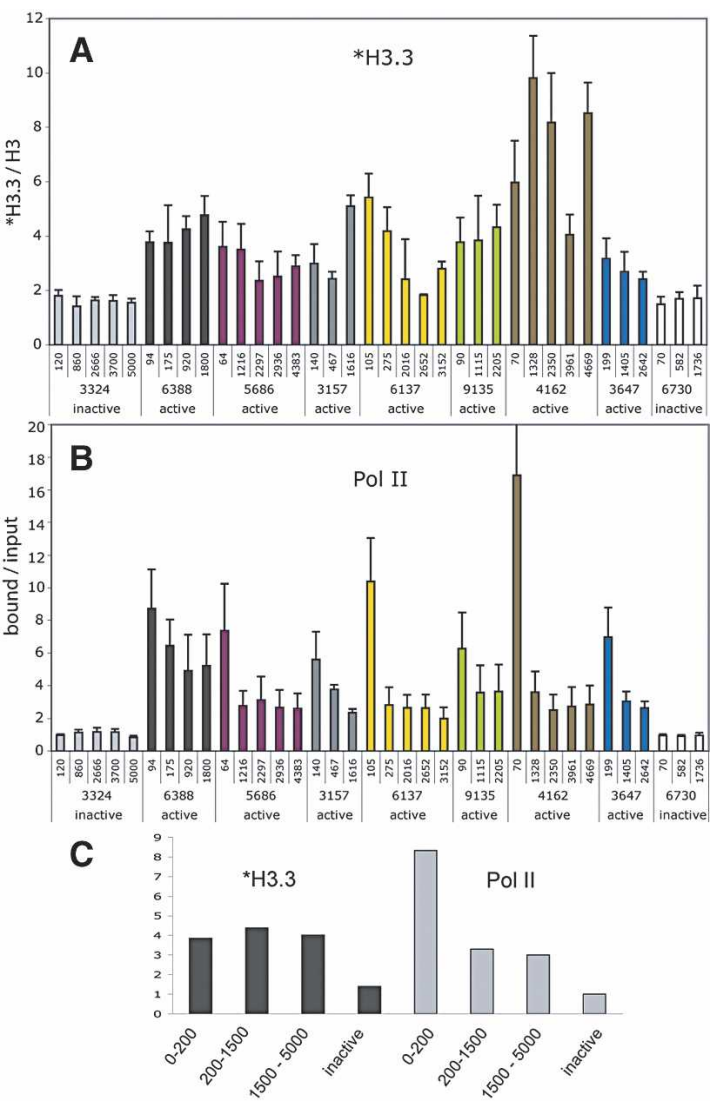

Figure 3. (A) Sites of H3.3 deposition. ChIP against the V5-tag was performed in cell pools expressing either ${ }^{\star} \mathrm{H} 3$ or ${ }^{\star} \mathrm{H} 3.3$ and abundance was determined at the same genes analyzed in Figure 2. The resulting enrichment was measured by real-time PCR and H3.3 abundance was calculated by dividing ${ }^{\star} \mathrm{H} 3.3$ by ${ }^{\star} \mathrm{H} 3$. Shown is the average and SD from three independent experiments. $(B)$ Polymerase abundance at the same set of sequences. ChIP against Ser5-P polymerase II was performed and subsequent real-time PCR was used to determine polymerase abundance. Values were calculated similarly to those in Figure 2. Shown is the average from three experiments. (C) Similar to Figure 3B, the average enrichments were calculated after grouping probes of active genes according to distance to start site. All probes at inactive genes were grouped separately. This illustrates that H3.3 and PolII show similar enrichments throughout transcribed regions. The higher enrichment of PolII at the promoter likely reflects early elongation events (see text).

fer around the polymerase, partial release or unfolding, and even temporary or stable dissociation (for review, see van Holde et al. 1992). Based on the recent observation by ChIP of reduced nucleosomal abundance at highly active genes, it was hypothesized that nucleosomes are displaced during transcription (Lee et al. 2004), as has been shown for the promoter region of the yeast PHO5 gene (Boeger et al. 2003; Reinke and Horz 2003). However, partial nucleosomal disassembly and rapid $\mathrm{H} 2 \mathrm{~A} /$ $\mathrm{H} 2 \mathrm{~B}$ exchange also occur transcription coupled (Jackson 1990; Thiriet and Hayes 2005) in a process catalyzed by the transcription elongation complex FACT (Belotserkovskaya et al. 2003). Thus reduced detection of nucleosomes at active genes could reflect transient disassembly, which could interfere with detection and/or crosslinking, rather than actual nucleosomal displacement.

The use of tagged variants allowed us to monitor nucleosomal abundance of specific H3 variants during and following a temporary induction of a heat-shockresponsive gene (HSP70). Heat-shock response leads to rapid release of polymerases already initiated at the promoter and provides a proven model system to study the molecular events involved in transcriptional elongation (Rougvie and Lis 1988).

We shifted Kc cells from $25^{\circ} \mathrm{C}$ to $37^{\circ} \mathrm{C}$ by adding preheated media, maintained these cells for $60 \mathrm{sec}$ at $37^{\circ} \mathrm{C}$, and then added a defined amount of cold media to rapidly return the cells to $25^{\circ} \mathrm{C}$ and to a noninduced state (Boehm et al. 2003). As expected, these conditions resulted in a strong induction of HSP70 expression (data not shown). During and after the induction we monitored polymerase abundance $673 \mathrm{bp}$ downstream of the promoter (Fig. 4A) in cell lines expressing either ${ }^{\star} \mathrm{H} 3$ or ${ }^{\star}$ H3.3. Consistent with the increase in RNA levels, we detected a strong increase in polymerase after the 1-min temperature shift. Upon 30 min recovery in noninducing conditions, polymerase levels decreased again and approached the level prior to induction. Thus the chosen conditions lead to a rapid and temporary induction of transcription. We next determined the abundance of ${ }^{\star} \mathrm{H} 3$ and ${ }^{\star} \mathrm{H} 3.3$ during this time course. At high polymerase levels, we observe a reduction in both histone variants by $40 \%$, suggesting that almost every second nucleosome is either displaced or inaccessible for detection under these conditions (Fig. 4B). This reduction is not limited to epitope containing histones since a similar decrease is detected with a variant unspecific antibody directed against the $\mathrm{C}$ terminus of $\mathrm{H} 3$ (Supplementary Fig. 1B). Moreover, such a reduction in nucleosomal density downstream of the promoter is not unique to the

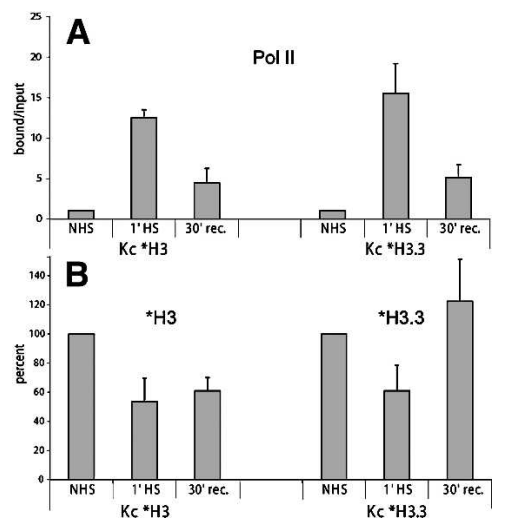

Figure 4. Histone displacement and variant incorporation during and following a temporary gene induction. $(A)$ RNA polymerase II abundance was measured at a position $673 \mathrm{bp}$ downstream of the promoter during and post-gene induction in cells expressing ${ }^{*} \mathrm{H} 3$ and ${ }^{\star} \mathrm{H} 3.3$. Levels prior to induction were set to 1 . Sixty seconds of induction lead to a $>12$-fold increase in polymerase at the gene. After 30 min recovery in noninducing conditions, the polymerase levels declined toward the level prior to induction. Shown is the average of three independent experiments $(B)$ ChIP against tagged variants during and post-gene induction. Levels of ${ }^{*} \mathrm{H} 3$ and ${ }^{*} \mathrm{H} 3.3$ prior to induction were set to $100 \%$. ${ }^{\star} \mathrm{H} 3$ and ${ }^{\star} \mathrm{H} 3.3$ declined to a similar extent upon activation at the $1^{\prime}$ time point. After 30 min recovery, ${ }^{\star} \mathrm{H} 3$ levels remained low and unchanged, while ${ }^{\star} \mathrm{H} 3.3$ behaved differently and more than regained its initial abundance. This specific gain of ${ }^{\star} \mathrm{H} 3.3$ was only detected in noninducing conditions and not during longer induction periods. Shown is the average and SD from four independent experiments. The change during recovery is highly significant for ${ }^{\star} \mathrm{H} 3.3$ and not significant for ${ }^{\star} \mathrm{H} 3(p=0.02$ vs. $p=0.7$, comparing ${ }^{*} \mathrm{H} 3$ and ${ }^{*} \mathrm{H} 3.3$ levels before and after recovery using a Student's $t$-test). 
activated HSP70: We observe an equally strong reduction at a highly expressed gene (CG4162) without heat induction (Supplementary Fig. 1), similar to observations in $S$. cerevisiae (Lee et al. 2004).

After 30 min recovery post-induction, we again determined the levels of both ${ }^{\star} \mathrm{H} 3$ and ${ }^{\star} \mathrm{H} 3.3$ at HSP70. At this time point, the level of ${ }^{\star} \mathrm{H} 3$ stays low and does not regain the level observed prior to induction (Fig. 4B). This stable loss of ${ }^{\star} \mathrm{H} 3$ levels can only be explained by nucleosomal displacement in trans, as a temporary lack of detection, due to partial disassembly, for example, should result in the return to initial levels upon reduced transcription.

Even though *H3.3 levels are also reduced during activated transcription, levels of this variant after the recovery phase exceed those observed prior to induction. In the context of the stable displacement of $\mathrm{H} 3$, we interpret this dynamic behavior of $\mathrm{H} 3.3$ to reflect the specific deposition of H3.3 following transcription-coupled displacement. This observation makes it unlikely that reduced detection of nucleosomes at transcribed regions is simply a consequence of nucleosome sliding (Langst et al. 1999; Whitehouse et al. 1999) or H2A/H2B dimer exchange (Thiriet and Hayes 2005). Rather, it provides evidence that nucleosomal eviction of $\mathrm{H} 3$ and $\mathrm{H} 3.3$ occurs during transcription, leading to an intermediate state of low nucleosomal abundance, which is subsequently compensated by H3.3 deposition.

\section{Conclusion}

We show that sites of H3.3 deposition have a nonuniform pattern of histone tail modifications, suggesting that variant deposition and targeting of the studied modifications are uncoupled. This observation makes it unlikely that H3.3 alone is sufficient to predetermine euchromatic tail modifications. However, our finding of H3.3 incorporation throughout all active genes is compatible with a role for displacement and variant deposition in erasing heterochromatic modifications, which could mediate a switch in epigenetic states. Recent reports of intergenic transcription through multigenic loci have led to the hypothesis that a "pioneering polymerase" would be required in order to open chromatin and to allow long-distance gene regulation (for review, see Morey and Avner 2004), a process that could involve displacement and H3.3 deposition, as previously hypothesized (Ahmad and Henikoff 2002a). If H3.3 deposition occurs at all transcribed regions, one would expect a shorter half-life for this variant, as it should be constantly replaced. Indeed the alfalfa homolog of H3.3 (Waterborg 1993) and Drosophila H3.3 (Schwartz and Ahmad 2005) have been shown to have a higher turnover rate than major H3.

Why are nucleosomes evicted during transcription? Displacement could result from positive supercoiling accumulating in front of the polymerase (van Holde et al. 1992), or it could be a catalyzed event in which nucleosomes are actively removed in order to facilitate transcription and/or to allow resetting of chromatin states.

While the exact mechanisms need to be determined, we note that transcription-coupled displacement and subsequent $\mathrm{H} 3.3$ deposition do not require that both events are directly linked. It is conceivable that H3.3 deposition is triggered by a system that detects regions of low nucleosomal abundance. If so, H3.3 deposition might not be limited to transcribed regions but may be a general feature of a chromosomal region with transiently reduced nucleosomal density, such as promoter distal hypersensitive sites, as well as other regions of chromatin reorganization, such as those undergoing DNA repair or protamine-histone exchange after fertilization.

\section{Materials and methods}

Histone variant constructs

H3 was PCR amplified from the plasmid HS-H3-GFP (Ahmad and Henikoff 2002b) and H3.3 from a cDNA library and cloned into pIB-V5/His Topo (Invitrogen). Primers are listed in the Supplemental Material.

Tissue culture and stable transfection

Drosophila Kc cells were kept in HyQ-SFX (Hyclone). Cells $\left(1.5 \times 10^{6}\right)$ were seeded and transfected with $1 \mu \mathrm{g}$ of plasmid DNA using Cellfectin (Invitrogen) according to the manufacturer's protocol. After $48 \mathrm{~h}$ selective medium containing $50 \mu \mathrm{g} / \mathrm{mL}$ Blasticidin (Fluka) was added. After 2 wk in selection Blasticidin concentration was reduced to $20 \mu \mathrm{g} / \mathrm{mL}$.

\section{ChIP}

Cells $\left(2 \times 10^{8}\right)$ were cross-linked with formaldehyde as described (Schübeler et al. 2004) with minor modifications. Sonication was performed in $5 \times 20 \mathrm{sec}$ in lysis buffer $(50 \mathrm{mM} \mathrm{HEPES} / \mathrm{KOH}$ at $\mathrm{pH} 7.5,500 \mathrm{mM} \mathrm{NaCl}$, $1 \mathrm{mM}$ EDTA, $1 \%$ Triton X-100, 0.1\% DOC, $0.1 \%$ SDS + complete protease inhibitors [Roche]). One hundred micrograms chromatin was used per IP, except $400 \mu \mathrm{g}$ for $\alpha$ V5. 3-5 $\mu$ g antibody was used per IP. Immunocomplexes were isolated by adding protein A-sepharose (polyclonal sera), protein A- and G-sepharose (V5), or IgM magnetic beads (PolII) followed by four washing steps: $2 \times$ lysis buffer, $1 \times$ DOC buffer $(10 \mathrm{mM}$ Tris at pH 8, 0.25 M LiCl, 0.5\% NP-40, 0.5\% DOC, 1 mM EDTA), $1 \times$ TE at $\mathrm{pH}$ 8. Reversal and DNA purification was as described (Schübeler et al. 2004). Antibody descriptions are listed in the Supplemental Material.

\section{Immunofluorescence}

Cells were seeded on polylysine coated coverslips and washed with PBS followed by a $10-\mathrm{min}$ incubation in $0.5 \%$ sodium citrate. Fixation was done in $4 \%$ paraformaldehyde and $0.3 \%$ Triton X-100 for $12 \mathrm{~min}$ at RT followed by two washes with PBS. After $30 \mathrm{~min}$ incubation in blocking buffer (PBS, 1\% BSA, 1\% goat serum) the primary antibody was added ( $\alpha$ V5 1/500, H3K4me2 1/200) for $1 \mathrm{~h}$ followed by two washes in PBS. Secondary antibody was added $(1 / 200)$ for $1 \mathrm{~h}$ followed by two washes in PBS before mounting in DAPI containing Vectashield (Vectorlabs).

\section{Real-time PCR}

PCR conditions and complete primer sequences are listed in the Supplemental Material.

\section{Acknowledgments}

We thank members of the Schübeler lab for suggestions; Antoine Peters for advice in microscopy; Bryan Turner for providing antibody; Susan Gasser, Mark Groudine, Antoine Peters, and Michael Weber for comments on the manuscript; and Steve Henikoff for DNA constructs and sharing data prior to publication. Work in the Schübeler lab is supported by the Novartis Research Foundation.

\section{References}

Ahmad, K. and Henikoff, S. 2002a. Histone H3 variants specify modes of chromatin assembly. Proc. Natl. Acad. Sci. 99 (Suppl. 4): $16477-$ 16484.

. 2002b. The histone variant H3.3 marks active chromatin by replication-independent nucleosome assembly. Mol. Cell 9: 1191-1200.

Belotserkovskaya, R., Oh, S., Bondarenko, V.A., Orphanides, G., Studitsky, V.M., and Reinberg, D. 2003. FACT facilitates transcriptiondependent nucleosome alteration. Science 301: 1090-1093.

Bernstein, B.E., Liu, C.L., Humphrey, E.L., Perlstein, E.O., and Schreiber, S.L. 2004. Global nucleosome occupancy in yeast. Genome Biol. 5: R62.

Bernstein, B.E., Kamal, M., Lindblad-Toh, K., Bekiranov, S., Bailey, D.K., Huebert, D.J., McMahon, S., Karlsson, E.K., Kulbokas III, E.J., Gin- 
geras, T.R., et al. 2005. Genomic maps and comparative analysis of histone modifications in human and mouse. Cell 120: 169-181.

Boeger, H., Griesenbeck, J., Strattan, J.S., and Kornberg, R.D. 2003. Nucleosomes unfold completely at a transcriptionally active promoter. Mol. Cell 11: 1587-1598.

Boehm, A.K., Saunders, A., Werner, J., and Lis, J.T. 2003. Transcription factor and polymerase recruitment, modification, and movement on dhsp70 in vivo in the minutes following heat shock. Mol. Cell. Biol. 23: $7628-7637$

Chow, C.M., Georgiou, A., Szutorisz, H., Maia, E.S.A., Pombo, A., Barahona, I., Dargelos, E., Canzonetta, C., and Dillon, N. 2005. Variant histone $\mathrm{H} 3.3$ marks promoters of transcriptionally active genes during mammalian cell division. EMBO Rep. 6: 354-360.

Felsenfeld, G. and Groudine, M. 2003. Controlling the double helix. Nature 421: 448-453.

Henikoff, S., Furuyama, T., and Ahmad, K. 2004. Histone variants, nucleosome assembly and epigenetic inheritance. Trends Genet. 20: 320-326.

Jackson, V. 1990. In vivo studies on the dynamics of histone-DNA interaction: Evidence for nucleosome dissolution during replication and transcription and a low level of dissolution independent of both. Biochemistry 29: 719-731.

Jones, J.C., Phatnani, H.P., Haystead, T.A., MacDonald, J.A., Alam, S.M. and Greenleaf, A.L. 2004. C-terminal repeat domain kinase I phosphorylates Ser2 and Ser5 of RNA polymerase II C-terminal domain repeats. J. Biol. Chem. 279: 24957-24964.

Kizer, K.O., Phatnani, H.P., Shibata, Y., Hall, H., Greenleaf, A.L., and Strahl, B.D. 2005. A novel domain in Set2 mediates RNA polymerase II interaction and couples histone H3 K36 methylation with transcript elongation. Mol. Cell. Biol. 25: 3305-3316.

Komarnitsky, P., Cho, E.J., and Buratowski, S. 2000. Different phosphorylated forms of RNA polymerase II and associated mRNA processing factors during transcription. Genes \& Dev. 14: 2452-2460.

Korber, P., Luckenbach, T., Blaschke, D., and Horz, W. 2004. Evidence for histone eviction in trans upon induction of the yeast PHO5 promoter. Mol. Cell. Biol. 24: 10965-10974.

Langst, G., Bonte, E.J., Corona, D.F., and Becker, P.B. 1999. Nucleosome movement by CHRAC and ISWI without disruption or trans-displacement of the histone octamer. Cell 97: 843-852.

Lee, C.K., Shibata, Y., Rao, B., Strahl, B.D., and Lieb, J.D. 2004. Evidence for nucleosome depletion at active regulatory regions genome-wide. Nat. Genet. 36: 900-905.

McKittrick, E., Gafken, P.R., Ahmad, K., and Henikoff, S. 2004. Histone $\mathrm{H} 3.3$ is enriched in covalent modifications associated with active chromatin. Proc. Nat1. Acad. Sci. 101: 1525-1530.

Morey, C. and Avner, P. 2004. Employment opportunities for non-coding RNAs. FEBS Lett. 567: 27-34.

O'Brien, T., Hardin, S., Greenleaf, A., and Lis, J.T. 1994. Phosphorylation of RNA polymerase II C-terminal domain and transcriptional elongation. Nature 370: 75-77.

Peters, A.H. and Schübeler, D. 2005. Methylation of histones: Playing memory with DNA. Curr. Opin. Cell Biol. 17: 230-238.

Reinke, H. and Horz, W. 2003. Histones are first hyperacetylated and then lose contact with the activated PHO5 promoter. Mol. Cell 11: 1599-1607.

Rougvie, A.E. and Lis, J.T. 1988. The RNA polymerase II molecule at the $5^{\prime}$ end of the uninduced hsp70 gene of $D$. melanogaster is transcriptionally engaged. Cell 54: 795-804.

Santos-Rosa, H., Schneider, R., Bernstein, B.E., Karabetsou, N., Morillon, A., Weise, C., Schreiber, S.L., Mellor, J., and Kouzarides, T. 2003. Methylation of histone H3 K4 mediates association of the Isw $1 \mathrm{p}$ ATPase with chromatin. Mol. Cell 12: 1325-1332.

Sarma, K. and Reinberg, D. 2005. Histone variants meet their match. Nat. Rev. Mol. Cell Biol. 6: 139-149.

Schotta, G., Ebert, A., Krauss, V., Fischer, A., Hoffmann, J., Rea, S., Jenuwein, T., Dorn, R., and Reuter, G. 2002. Central role of Drosophila SU(VAR)3-9 in histone H3-K9 methylation and heterochromatic gene silencing. EMBO J. 21: 1121-1131.

Schübeler, D., Scalzo, D., Kooperberg, C., Van Steensel, B., Delrow, J., and Groudine, M. 2002. Genome-wide DNA replication profile for Drosophila melanogaster: A link between transcription and replication timing. Nat. Genet. 32: 438-442.

Schübeler, D., MacAlpine, D.M., Scalzo, D., Wirbelauer, C., Kooperberg,
C., van Leeuwen, F., Gottschling, D.E., O'Neill, L.P., Turner, B.M., Delrow, J., et al. 2004. The histone modification pattern of active genes revealed through genome-wide chromatin analysis of a higher eukaryote. Genes \& Dev. 18: 1263-1271.

Schwartz, B.E. and Ahmad, K. 2005. Transcriptional activation triggers deposition and removal of the histone variant H3.3. Genes \& Dev. 19: 804-814.

Sims III, R.J., Belotserkovskaya, R., and Reinberg, D. 2004. Elongation by RNA polymerase II: The short and long of it. Genes \& Dev. 18: 2437 2468.

Strahl, B.D. and Allis, C.D. 2000. The language of covalent histone modifications. Nature 403: 41-45.

Tagami, H., Ray-Gallet, D., Almouzni, G., and Nakatani, Y. 2004. Histone H3.1 and H3.3 complexes mediate nucleosome assembly pathways dependent or independent of DNA synthesis. Cell 116: 51-61.

Thiriet, C. and Hayes, J.J. 2005. Replication-independent core histone dynamics at transcriptionally active loci in vivo. Genes \& Dev. 19: 677-682.

Turner, B.M. 2002. Cellular memory and the histone code. Cell 111: $285-291$.

- 2005. Reading signals on the nucleosome with a new nomenclature for modified histones. Nat. Struct. Mol. Biol. 12: 110-112.

van Holde, K.E., Lohr, D.E., and Robert, C. 1992. What happens to nucleosomes during transcription? J. Biol. Chem. 267: 2837-2840.

Waterborg, J.H. 1993. Dynamic methylation of alfalfa histone H3. J. Biol. Chem. 268: 4918-4921.

Whitehouse, I., Flaus, A., Cairns, B.R., White, M.F., Workman, J.L., and Owen-Hughes, T. 1999. Nucleosome mobilization catalysed by the yeast SWI/SNF complex. Nature 400: 784-787. 


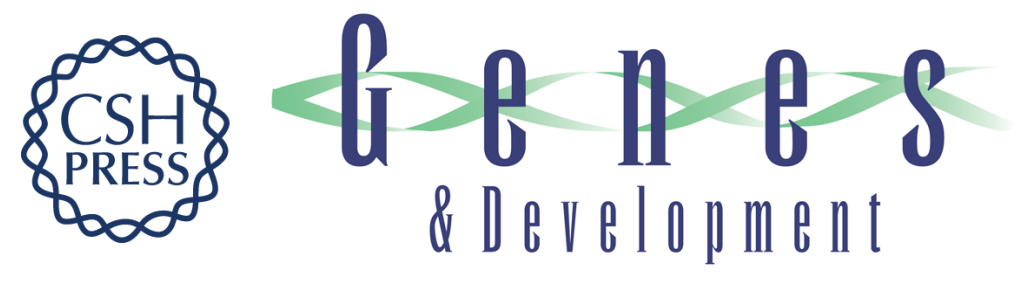

\section{Variant histone H3.3 is deposited at sites of nucleosomal displacement throughout transcribed genes while active histone modifications show a promoter-proximal bias}

Christiane Wirbelauer, Oliver Bell and Dirk Schübeler

Genes Dev. 2005, 19:

Access the most recent version at doi:10.1101/gad.347705

Supplemental http://genesdev.cshlp.org/content/suppl/2005/07/29/19.15.1761.DC1

Material

References This article cites 38 articles, 15 of which can be accessed free at: http://genesdev.cshlp.org/content/19/15/1761.full.html\#ref-list-1

License

Email Alerting Receive free email alerts when new articles cite this article - sign up in the box at the top Service right corner of the article or click here.

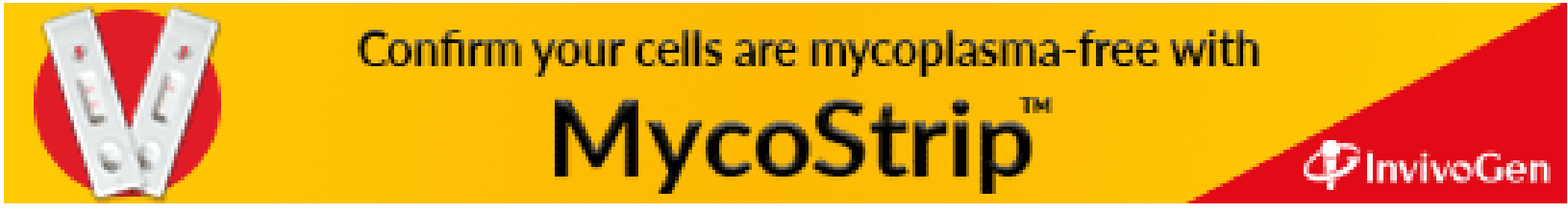

